PNL-SA-25518

\title{
TEMPERATURE AND STRAIN-RATE EFFECTS ON DEFORMATION MECHANISMS IN IRRADIATED STAINLESS STEEL
}

J. L. Brimhall

J. I. Cole

J. S. Vetrano

S. M. Bruemmer

November 1994

Presented at the

Materials Research Society Annual Fall Meeting

November 27 - December 2, 1994

Boston, Massachusetts

Prepared for

the U.S. Department of Energy

under Contract DE-AC06-76RLO 1830

Pacific Northwest Laboratory

Richland, Washington 99352

\section{DISCLAIMER}

This report was prepared as an account of work sponsored by an agency of the United States Government. Neither the United States Government nor any agency thereof, nor any of their employees, makes any warranty, express or implied, or assumes any legal liability or responsibility for the accuracy, completeness, or usefulness of any information, apparatus, product, or process disclosed, or represents that its use would not infringe privately owned rights. Reference herein to any specific commercial product, process, or service by trade name, trademark, manufacturer, or otherwise does not necessarily constitute or imply its endorsement, recommendation, or favoring by the United States Government or any agency thereof. The views and opinions of authors expressed herein do not necessarily state or reflect those of the United States Government or any agency thereof. 


\section{DISCLAIMER}

Portions of this document may be illegible in electronic image products. Images are produced from the best available original document. 


\section{TEMPERATURE AND STRAIN-RATE EFFECTS ON DEFORMATION MECHANISMS IN IRRADIATED STAINLESS STEEL}

J. L. BRIMHALL, J. I. COLE, J. S. VETRANO AND S. M. BRUEMMER, Pacific Northwest Laboratory(a), P.O. Box 999, Richland, WA 99352

\section{ABSTRACT}

Analysis of the deformation microstructures in ion-irradiated stainless steel shows twinning to be the predominant deformation mode at room temperature. Dislocation channelling also occurs under slow strain rate conditions. Stresses required for twinning were calculated by the model of Venables and are compatible with observed yield stresses in neutron-irradiated material if loops are the principal twin source. Computation of the expected radiation hardening from the defect structure, based on a simple model, is consistent with yield strengths measured on neutron-irradiated steels. Lower yield stresses and greater thermal energy at $288^{\circ} \mathrm{C}$ lessen the probability of twinning and dislocation channeling becomes the primary deformation mode at the higher temperature. However, preliminary early results show that some twinning does occur in the irradiated stainless steel even at the higher temperature when higher strain rates are used.

\section{INTRODUCTION}

Intergranular cracking of stainless steel core components in light-water reactor (LWR) environments is a signifcant concern. While the issue of local compositional change such as radiation-induced grain boundary segregation has received considerable study, changes in basic deformation behavior in these materials caused by the irradiation have not received much emphasis. There have been relatively few fundamental studies relating defect structure and mechanical behavior in stainless steel for the dose and temperature range of interest for LWRs 1,2. Most work has involved the high-dose and high-temperature range of interest to fast reactors ${ }^{3}$. Deformation studies on irradiated pure metals, e.g. copper, have shown significant effects such as dislocation channelling 4,5 and suggest that the radiation microstructure can promote highly localized deformation

As part of a basic study on irradiation effects on stress corrosion cracking, the microstructure and deformation modes are being analyzed in irradiated austenitic stainless steels. To evaluate a wide range of conditions, initial studies have used ion irradiation to produce microstructures relevant to LWR core components. Previous work6-8 has revealed significant effects of the defect microstructure on deformation modes. The current study extends the initial work and correlates the results with simple models of deformation behavior.

(a) Pacific Northwest laboratory is operated by Battelle Memorial Institute for the U. S. Department of Energy 


\section{EXPERIMENTAL TECHNIQUE}

A solution annealed $304 \mathrm{~L}$ stainless steel was irradiated with $5 \mathrm{MeV} \mathrm{Ni}$ ions to doses between 1 and 5 displacements per atom (dpa) at $500^{\circ} \mathrm{C}$. Because of the high damage rate during ion irradiation, this produces a microstructure which is similar to that produced at about $300^{\circ} \mathrm{C}$ in neutron irradiations. After irradiation, the material was pulled in tension up to $10 \%$ strain at room temperature and at $288^{\circ} \mathrm{C}$ at strain rates of $2 \times 10^{-4}$ and $2 \times 10^{-6} \mathrm{sec}^{-1}$. Surface analysis showed the plastic strain in the ion-irradiated region to be somewhat less than the bulk strain. The irradiated and deformed regions were subsequently analyzed by TEM. Additional details of the material, irradiation, and testing technique can be found in the previous reports6-8.

\section{RESULTS}

The principal effect of irradiation on the microstructure was the formation of dislocation loops. Small isolated dislocation loops were observed after the lower dose of $1 \mathrm{dpa}$ with an average size of about $8 \mathrm{~nm}$ and a density of $1 \times 1022 / \mathrm{m}^{3}$. Defects that could not be resolved as loops were labeled as black spots. Stacking faults could be resolved in the larger loops. At the highest dose of $5 \mathrm{dpa}$, the loop density increased to $3 \times 10^{22} / \mathrm{m}^{3}$ and the average size was about $20 \mathrm{~nm}$. Some of the larger loops had also unfaulted and formed perfect loops. Typical microstructure for an irradiation dose of $3 \mathrm{dpa}$ is shown in figure 1 . The dislocation network density was estimated as $1 \times 10^{14} / \mathrm{m}^{2}$ in the higher dose material. This presumably is a result of the unfaulting and interaction of the larger loops. The dislocation network density of the lower dose material did not appear to be different than the unirradiated material.

After relatively small amounts of strain, deformation twinning is the predominant deformation mode at $25^{\circ} \mathrm{C}$ particular;y at the high strain rate. An example of the deformation twinning after $5 \%$ strain in the material irradiated to 5 dpa is shown in figure 2. The width of the twins varied from 50 to $200 \mathrm{~nm}$ and the spacing was about 0.2 micron. In material irradiated to $1 \mathrm{dpa}$, extensive faults were observed after small strains. Twins could be resolved but were extremely narrow, $<20 \mathrm{~nm}$, with a spacing of only about 0.1 micron. At the lower strain rate, dislocation channels as indicated by cleared paths through the defect structure were occasionally observed in addition to twins. In contrast, the unirradiated material showed initial planar deformation and dislocation pile-ups; however, dislocation tangling was evident with increasing strain. No deformation twins were observed in the unirradiated material up to $10 \%$ strain.

Dislocation channelling was the predominant deformation mode during straining at $288^{\circ} \mathrm{C}$ under the slower strain rate of $2 \times 10^{-6} / \mathrm{sec}^{-1}$. No twinning was observed in the microstructure under these conditions. The channels are difficult to resolve as the width is only of the order of $15 \mathrm{~nm}$, figure 3 . The spacing is about $150 \mathrm{~nm}$, indicating a very high density of channels. Some deformation twinning occurred during deformation at $288^{\circ} \mathrm{C}$ when the higher strain rate of $2 \times 10^{-4} \mathrm{sec}^{-1}$ was used in the irradiated sample. In this case, deformation involved both twinning and dislocation channelling. 


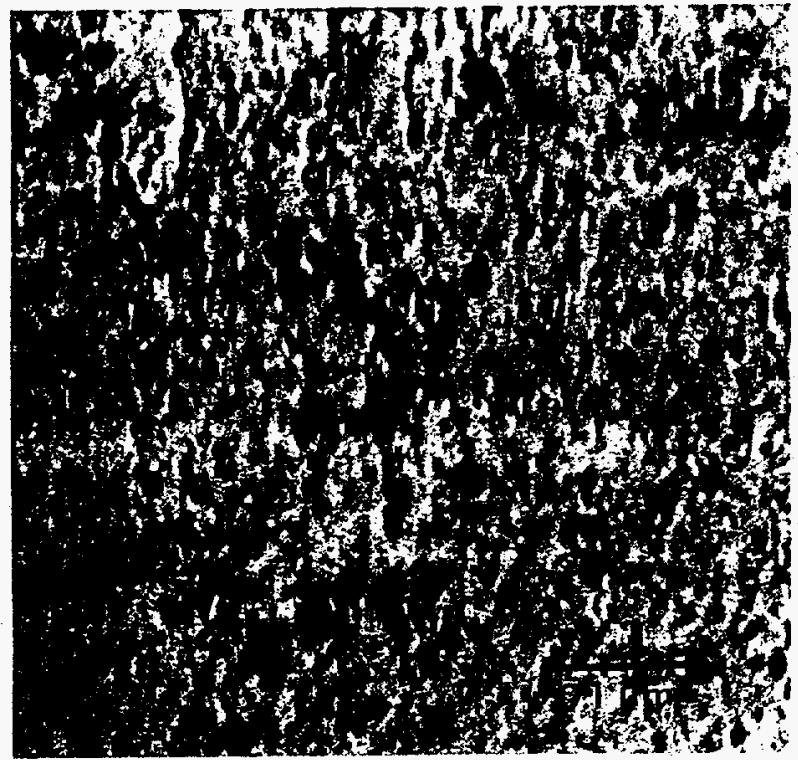

Figure 1. Microstructure of 304 stainless steel, ion irradiated to $3 \mathrm{dpa}$ at $500^{\circ} \mathrm{C}$.

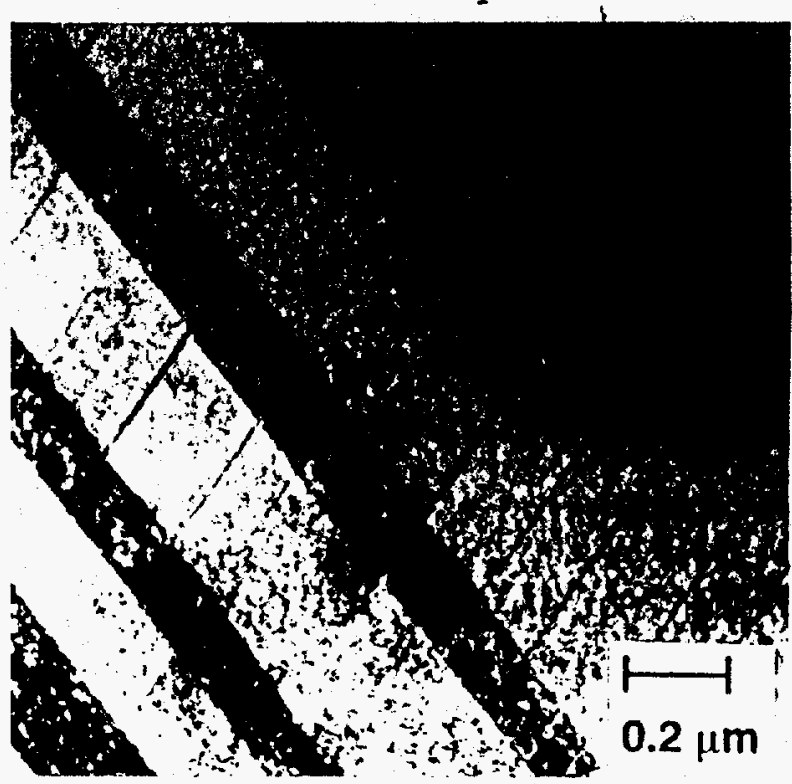

Figure 2. Deformation twins in ion irradiated 304 stainless steel, deformed $5 \%$ at room temperature.

\section{DISCUSSION}

Deformation twinning in the irradiated material can be rationalized based on the early work of Venables 9 . The stress for twinning is given by :

$$
n \sigma T=y / b+\mu b / 2 a_{0}
$$

Where $n=$ stress concentration factor, $\sigma_{T}=$ critical twinning stress, $y=$ stacking fault energy, $\mu=$ shear modulus, $b=$ burgers vector and $a_{0}=$ radius of the twin source. Venables has shown how radiation-produced dislocation loops can serve as twin source 10 . Based on equation 1 and assuming $2 \mathrm{a}_{0}$ is the loop diameter, the stress required for twinning is shown as a function of loop size in figure 4. For a typical $y$ value of $15 \mathrm{~mJ} / \mathrm{m}^{2}$ for 304 stainless and an average size loop of $20 \mathrm{~nm}$, the stress is over $1000 \mathrm{MPa}$. However, loops up to $30 \mathrm{~nm}$ are observed after $5 \mathrm{dpa}$ for which the twin stress is only $700 \mathrm{MPa}$. If the stress necessary for conventional dislocation glide is greater than this, twins should nucleate.

The available data from mechanical tests indicate a large increase in the yield strength of stainless steel after neutron irradiation near $300^{\circ} \mathrm{C}, 6,11$. Figure 5 is a plot of the room temperature yield strength as a function of dose for 304 stainless steel neutron irradiated at $288^{\circ} \mathrm{C} 11$. After several dpa (fluence $>1 \times 10^{21} \mathrm{n} / \mathrm{cm}^{2}$ ), the yield strength is in the range of the twinning stress and deformation twinning would be expected. The radiation-induced microstructure not only provides a source for deformation twins but increases the stress required for conventional dislocation slip. 
To determine if the microstructure is compatible with the increased strength, a dispersed barrier hardening model 12,13 was used to compute a hypothetical strength. The two components contributing to the hardening are the dislocation loops and dislocation network. The increase in the resolved shear stress due to loops is given by, $\Delta \tau_{1}=\alpha \mu b(N d)^{1 / 2}$ and that due to dislocations is given by $\Delta \tau_{n}=\alpha \mu b(g)^{1 / 2}$ where $\mathrm{N}=$ loop density, $\mathrm{d}=$ loop diameter, $\mathrm{e}=$ network density and $\alpha$ is a constant near 0.4 for loops and 0.2 for the dislocation network 13 . Using the average values for the loop diameter and the loop number density given previously, $\Delta \tau_{1}=70 \mathrm{MPa}$ after $1 \mathrm{dpa}$ and $180 \mathrm{MPa}$ after $5 \mathrm{dpa}$. For the $5 \mathrm{dpa}$ irradiation, there is the contribution from the network which is about $50 \mathrm{MPa}$ assuming a density of $1014 / \mathrm{m}^{2}$. Therefore, the total increase in shear stress, $\Delta \tau_{1}+\Delta \tau_{n}$, is $70 \mathrm{MPa}$ for $1 \mathrm{dpa}$ and about $230 \mathrm{Mpa}$ for $5 \mathrm{dpa}$. To convert from a resolved shear stress to a uniaxial tensile stress, the resolved shear stress is multiplied by a factor of three, 13 which gives 210 and 690 MPA, respectively. The total yield strength is $\sigma_{0}+\Delta \sigma_{i}$, where $\sigma_{0}$ is the yield strength of unirradiated steel. Assuming an average value of $250 \mathrm{MPa}$ for $\sigma_{0}$ at room temperature, the total yield strength is computed to be 460 and $840 \mathrm{MPa}$ for doses of 1 and 5 dpa respectively.

Plotting of the calculated yield strengths with the data for room temperature deformation in figure 5 shows them to be consistent with the measured values considering that stainless steels of different compositions and irradiation histories are being compared. It is believed that the agreement is close enough to demonstrate that the ion irradiation is adequately simulating neutron-induced microstructures and hence neutron-induced strengthening. This is further supported by a temperaturedose-microstructure map developed by Maziasz ${ }^{3}$ and a very recent review by Lucas ${ }^{13}$, in which the microstructure after neutron irradiation at $300^{\circ} \mathrm{C}$ to doses between 1 and 10 dpa should consist primarily of black spots and Frank loops.

At the higher deformation temperature, several factors contribute to lessen the probability of twinning in the stainless steel. Data from a number of tests of 304 stainless steel, irradiated at $288^{\circ} \mathrm{C}$ and tested at $288^{\circ} \mathrm{C}$, show a general increase in yield strength with dose but with considerable scatter, figure 66 . The average value is somewhat lower than observed at room temperature. Larger twin sources, e.g. loops approaching $50 \mathrm{~nm}$ in diameter, would be required to bring the twin stress down into the observed yield range. For the microstructure observed in this study there are few loops of this size. The stacking fault energy in stainless steel also increases with temperature 14 which increases the twinning stress. The higher stacking fault energy and the increase in thermal energy will also make cross slip easier. Dislocation glide processes which create defect-free channels will then be more probable at the higher temperature. Dislocation channels have been observed in a number of irradiated and deformed materials, all of which have relatively high stacking fault energies 5 .

Conclusions about the effect of strain rate can only be qualitative at the present time. An increase in strain rate increases the flow stress so the observations of some twinning at the higher strain rate at $288^{\circ} \mathrm{C}$ shows the proper trend. Conversely, the slower strain rate at room temperature allows sufficient time for the dislocation/defect interactions which are necessary to clear out the channels. 


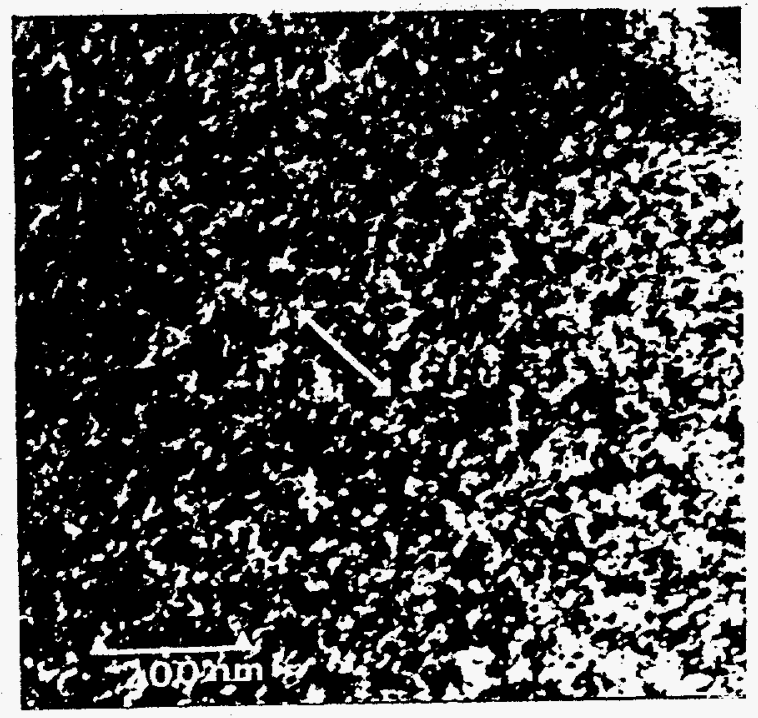

Figure 3. Narrow dislocation channels in irradiated 304 , stainless steel, deformed $5 \%$ at $288^{\circ} \mathrm{C}$.

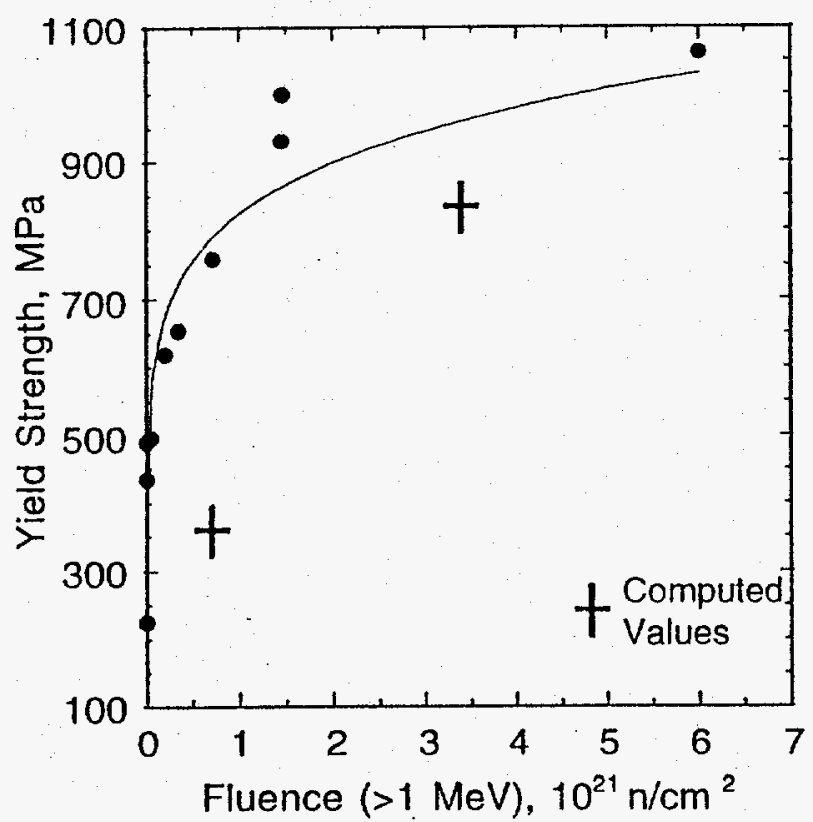

Figure 5. Dose dependence of yield strength in 304 stainless steel neutron irradiated at $288^{\circ} \mathrm{C}$ and tested at room temperature. Data from ref. 11

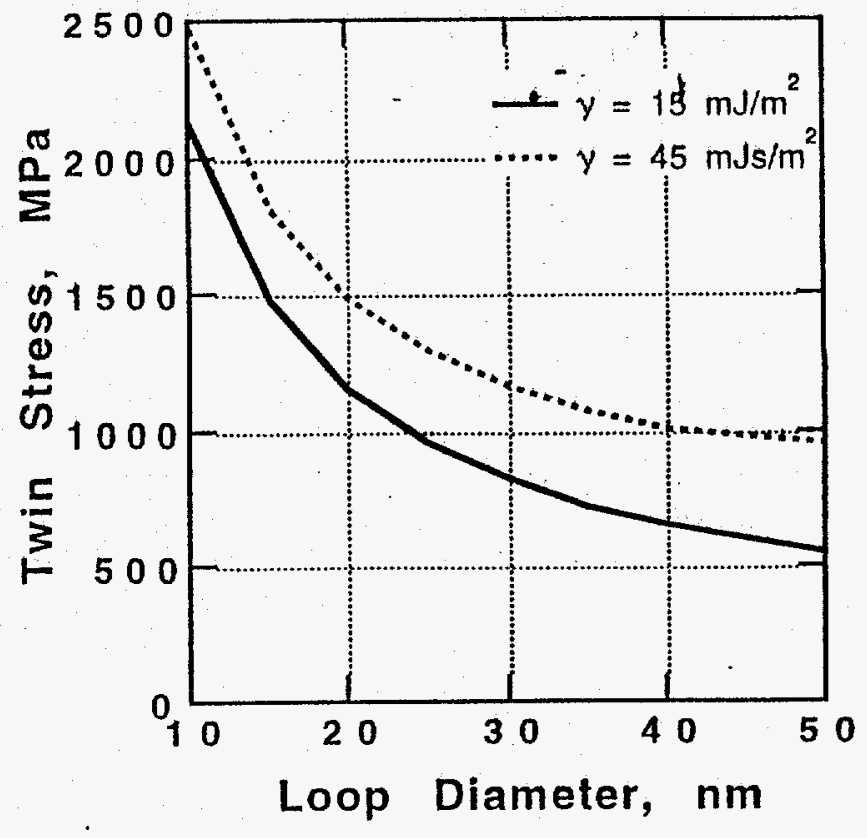

Figure 4. Required stress for twinning as function of loop diameter based on equation 1.

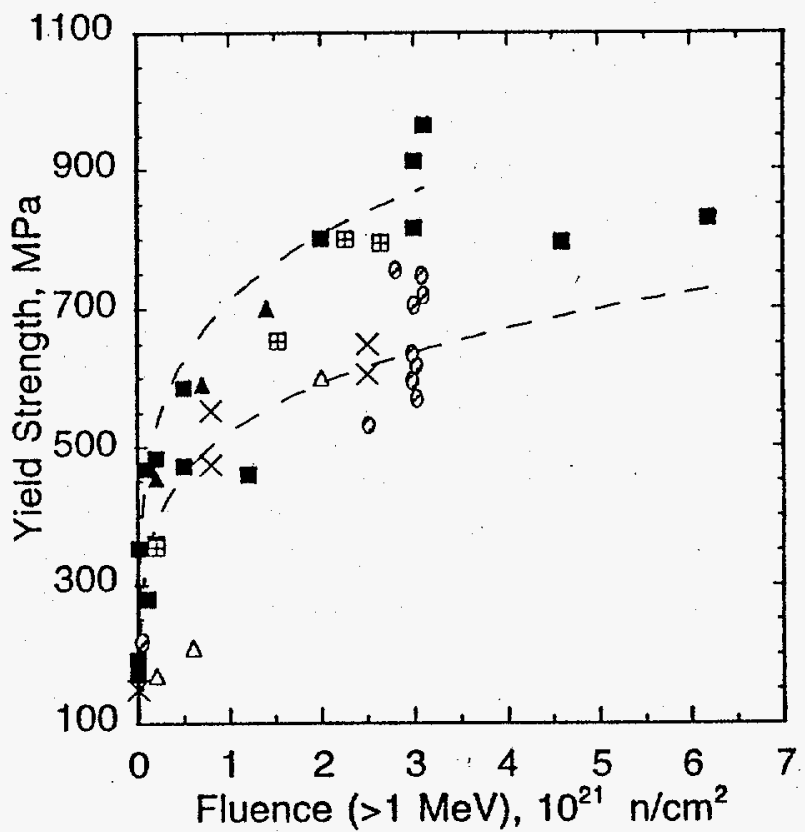

Figure 6. Dose dependence of yield strength in several 304 stainless steels irradiated at $288^{\circ} \mathrm{C}$ and tested at $288^{\circ}$. Data from ref. 6. $\left(0.7 \times 10^{21} \mathrm{n} / \mathrm{cm}^{2}=1 \mathrm{dpa}\right)$ 


\section{CONCLUSIONS}

Twinning is the predominant deformation mode in ion irradiated stainless steel deformed at room temperature but dislocation channelling also occurs when a lower strain rate is used. Dislocation channeling is typically observed during $288^{\circ} \mathrm{C}$ deformation, but twinning does occur when a high strain rate is used. The calculated stresses required for twinning, assuming the dislocation loops to be twin sources, are compatible with observed yield strengths in neutron-irradiated material deformed at room temperature. Computation of the expected radiation hardening from the defect structure is in reasonable agreement with the increase in the reported yield strength. The lower yield strengths at $288^{\circ} \mathrm{C}$ reduce the probability of deformation twinning at this temperature, at least in the early stages of deformation.

\section{ACKNOWLEDGMENT}

This work was supported by the Office of Basic Energy Science, Division of Materials Science, U.S. Depártment of Energy under contract DE-AC06-76RLO-1830.

\section{REFERENCES}

1. E. E. Bloom, W. R. Martin, J. O. Stiegler and J. R. Weir, Jr., J. Nucl. Mat., 22, 68 (1967).

2. J. O. Stiegler and J. R. Weir, Jr., ORNL -TM-2019, 1968.

3. P. J. Maziasz and C. J. McHargue, International Materials Review, 32, 190 (1987).

4. J. V. Sharp, Phil. Mag., 16, 77 (1967).

5. M. S. Wechsler, in The Inhomogeneity of Plastic Deformation, (ASM, Metals Park, $\mathrm{OH}, 1973)$, p. 19.

6. S. M. Bruemmer, J. I. Cole, J. L. Brimhall, R. D. Carter and G. S. Was in 6th Intl. Symp. on Environmental Degradation of Materials in Nuclear Power SystemsWater Reactors, edited by R.E. Gold and E. P. Simonen (The Mineral, Metals and Materials Soc., 1993), p. 537.

7. J. L. Brimhall, J. I. Cole and S. M. Bruemmer, Scripta Met. and Mat., 11, 1473 (1994).

8. J. I. Cole and S. M. Bruemmer, to be published in J. Nucl. Mat.

9. J. A. Venables, in Deformation Twinning, edited by R. E. Reed-Hill, J. P. Hirth and H. C. Rogers, (Gordon and Breach, New York, 1964), p. 111.

10. J. A. Venables, Phil. Mag., 6, 379 (1961).

11. J. E. Irvin, A. L. Bement and R. G. Hoagland, in Flow and Fracture of Metals and Alloys in Nuclear Environments, STP 380 (ASTM, Philadelphia, 1965), p. 236.

12. M. L. Grossbeck, P. J. Maziasz and A. F. Rowcliffe, J. Nucl. Mat., 191-194, 808 (1992).

13. G. E. Lucas, J. Nucl. Mat., 206, 287 (1993)

14. L. Remy, Acta Met., 25, 173 (1977). 